\title{
INVENTARISASI JENIS DAN STUDI KOMPOSISI PADA CAPUNG (ANISOPTERA) DAN CAPUNG-JARUM (ZYGOPTERA) DI KAWASAN KAMPUNG BARU, DESA TAMBAK SUMUR, KECAMATAN WARU, KABUPATEN SIDOARJO, JAWA TIMUR
}

\author{
Muhammad Muhibbuddin Abdillah \\ Universitas Islam Negeri Sunan Ampel Surabaya \\ abdillah.kutrik@gmail.com
}

\begin{abstract}
ABSTRAK
Indonesia merupakan negara dengan sumber plasma nutfah yang sangat melimpah sehingga memiliki julukan Megabiodiversity Country. Bentang alam berupa dataran rendah umumnya berupa perkotaan dengan pembangunan yang sangat pesat sehingga berpotensi menimbulkan dampak lingkungan. Data biodiversitas termasuk capung dan capung-jarum di kawasan perkotaan kurang lengkap dan tidak berulang karena minimnya penelitian. Kawasan Kampung Baru, Kecamatan Waru, Kabupaten Sidoarjo, Jawa Timur memiliki potensi keberadaan capung dan capung-jarum yang belum pernah dipelajari sebelumnya. Penelitian ini bertujuan untuk menginventarisasi dan mempelajari komposisi capung dan capung-jarum. Observasi dilaksanakan dengan pendekatan metode photographic approach selama Maret - Agustus 2020. Berdasarkan hasil penelitian, terdapat 16 spesies dari 3 famili capung dan capung-jarum di Kawasan Kampung Baru. Ditemukan juga spesies dengan kategori hampir terancam (NT) Teinobasis euglena (Coenagrionidae).
\end{abstract}

Kata Kunci Kawasan urban, Teinobasis euglena, Near-threatened

\begin{abstract}
Indonesia is a country with abundant sources of germplasm, called Megabiodiversity Country. Lowland landscapes are generally urban areas with very rapid development, with the potential to have environmental impacts. Data on biodiversity including dragonflies and damselflies in urban areas are incomplete and not in series due to the lack of research. The Kampung Baru area, Sidoarjo Regency, East Java, has a potential diversity of dragonflies and damselflies that has never been studied before. This study aims to make an inventory and considering the composition of dragonflies and damselflies. The observation was conducted using the photographic approach during March - August 2020. Based on the research results, there were 16 species from 3 families of dragonflies and damselflies in the Kampung Baru area. A near-threatened (NT) species, Teinobasis euglena (Coenagrionidae) was also found.
\end{abstract}

Keywords: Urban areas, Teinobasis euglena, Near-threatened

\section{PENDAHULUAN}

Indonesia merupakan negara yang memiliki biodiversitas atau sumber plasma nutfah yang sangat melimpah sehingga dijuluki Megabiodiversity Country (Rani \& Islami, 2014). Ring of Fire yang melintasi Indonesia menyebabkan geomorfologi (bentang alam) Indonesia yang beragam. Geomorfologi tersebut masing-masing memiliki ciri yang dapat dilihat dari sudut pandang biodiversitas (Yuliawati et al., 2016).
Bentang alam Indonesia sangat beragam, mulai dari pegunungan, perbukitan, dataran tinggi, dataran rendah, danau, sungai, pesisir, dan lautan. Salah satu daerah dengan kemajuan pembangunan yang sangat pesat adalah daerah pesisir dan dataran rendah (Yuliawati et al., 2016). Daerah pesisir dan dataran rendah umumnya berupa perkotaan karena lokasinya yang dekat dengan lautan sehingga memungkinkan kapal-kapal besar berlabuh dan memudahkan transportasi. Perkotaan dengan 
Muhammad Muhibbuddin Abdillah, Inventarisasi Jenis dan Studi Komposisi Pada Capung (Anisoptera) dan Capung-Jarum (Zygoptera) di Kawasan Kampung Baru, Desa Tambak Sumur, Kecamatan Waru, Kabupaten Sidoarjo, Jawa Timur Jurnal Biolokus: Jurnal Penelitian Pendidikan Biologi Dan Biologi Vol.3 (2)

pertumbuhannya yang pesat selalu lahan di Kawasan Kampung Baru yang mengesampingkan dampak pembangunan sebelumnya merupakan persawahan menjadi terhadap lingkungan. Bahkan ahli-ahli permukiman terjadi sangat pesat. Kebanyakan konservasi pada umumnya lebih memperhatikan flora dan fauna yang terdapat di kawasan konservasi saja. Biodiversitas di sekitar perkotaan bahkan tidak memiliki data yang lengkap dan berulang.

Insekta merupakan salah satu kelas pada Filum Arthropoda yang tersebar luas di berbagai kawasan termasuk kawasan perkotaan (Rezzafiqrullah et al., 2019). Tingkatan takson di bawah Kelas Insekta terdiri atas setidaknya 20 ordo (Kjer, 2004). Odonata adalah salah satu ordo dalam Kelas Insekta yang dapat ditemukan di berbagai kondisi habitat dengan ekosistem perairan (Setiyono et al., 2017).

Ordo Odonata terdiri atas Subordo Anisoptera (capung) dan Subordo Zygoptera (capung-jarum). Serangga ini mengalami perkembangan hemimetabola (metamorfosis tidak sempurna), dengan fase pradewasa (naiad) berada di dalam air dan fase dewasa (imago) bersifat aerial dan sering terbang sehingga mudah diamati (Setiyono et al., 2017).

Desa Tambak Sumur merupakan sebuah kawasan urbanisasi karena berbatasan langsung dengan Kota Surabaya. Alih fungsi persawahan di daerah ini juga berfungsi sebagai kolam ikan dan tambak tradisional. Keberadaan kolam ikan dan tambak tersebut sangat mendukung keberadaan serangga seperti capung dan capung-jarum. Selain itu, lokasi Desa Tambak Sumur berada di dataran rendah sehingga menyebabkan terjadinya genangan air walaupun dengan sedikit hujan yang terjadi. Potensi keberadaan capung dan capung-jarum di Desa Tambak Sumur cukup tinggi, namun belum tersedia data mengenai keanekaragaman capung tersebut. Penelitian ini bertujuan untuk mengungkap jenis-jenis capung dan capungjarum yang terdapat di Kawasan Kampung Baru, Desa Tambak Sumur, Kecamatan Waru, Kabupaten Sidoarjo, Jawa Timur.

\section{METODE}

\section{Lokasi Studi}

Penelitian ini dilakukan di Kawasan Kampung Baru, Desa Tambak Sumur, Kecamatan Waru, Kabupaten Sidoarjo. Observasi dilakukan pada berbagai jenis tutupan lahan yang terdiri atas permukiman, aliran drainase, kolam ikan, lapangan rumput dan rawa-rawa. Tata letak lokasi penelitian dapat dilihat pada peta di Gambar 1.

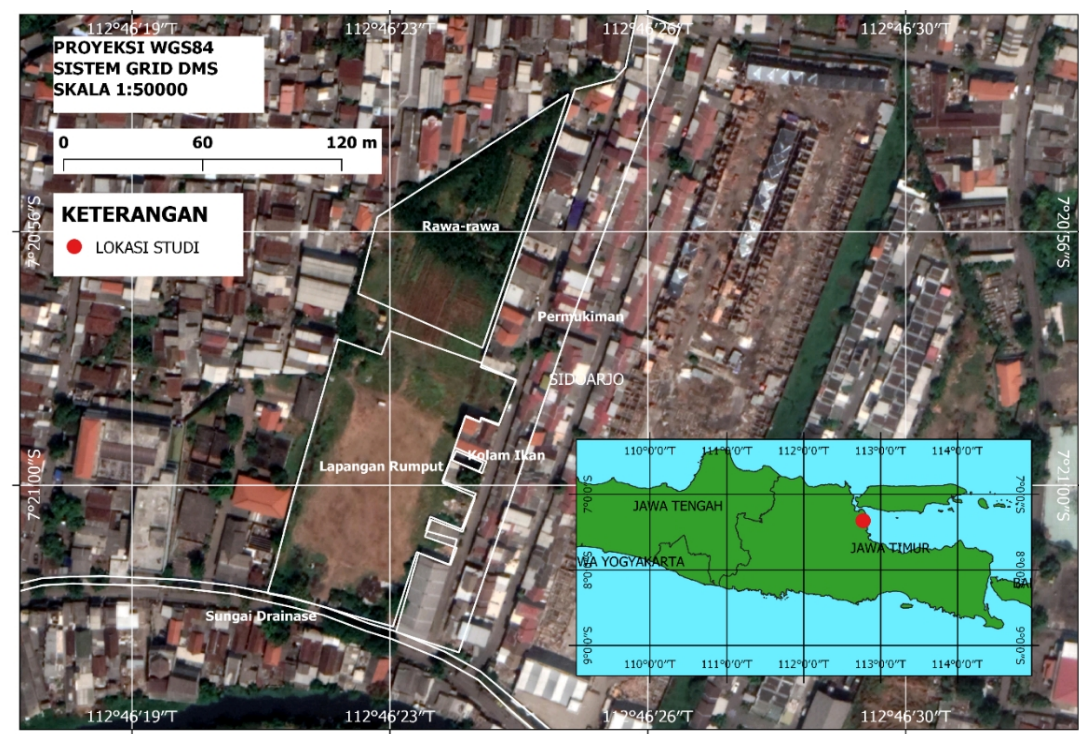

Gambar 1. Peta Lokasi Penelitian (Sumber: Dimodifikasi dari Google Maps) 
Muhammad Muhibbuddin Abdillah, Inventarisasi Jenis dan Studi Komposisi Pada Capung

(Anisoptera) dan Capung-Jarum (Zygoptera) di Kawasan Kampung Baru, Desa Tambak Sumur, Kecamatan Waru, Kabupaten Sidoarjo, Jawa Timur

Jurnal Biolokus: Jurnal Penelitian Pendidikan Biologi Dan Biologi Vol.3 (2)

\section{Pengambilan Data}

Data capung dan capung-jarum diambil menggunakan metode "Photographic Approach" selama bulan Maret - Agustus 2020. Capung dan capung-jarum yang ditemukan di lokasi penelitian difoto dan dilakukan pencatatan lokasi penemuan. Identifikasi dilakukan melalui foto yang dibuat saat pengamatan (Janra, 2018). Observasi dilakukan setiap dua minggu sekali dengan melakukan jelajah pada lokasi penelitian. Waktu yang digunakan adalah di awal dan akhir dari jam aktif capung dan capung-jarum yaitu 07:00 - 09:00 WIB dan 16:00 - 18:00 WIB.

\section{Analisis Data}

Data hasil observasi dihitung Frekuensi Kehadiran pada masing-masing spesies ditemukan menggunakan rumus sebagai berikut:

$$
\mathrm{FK}=\frac{(\text { plot ditemukan spesies i })}{(\text { jumlah keseluruhan plot })} \times 100 \%
$$

Analisis komposisi famili pada masingmasing lokasi dilakukan menggunakan Microsoft Office Excel 2013. Kelas masingmasing lokasi berdasarkan spesies yang ditemukan dianalisis dan disajikan menggunakan dendogram menggunakan SPSS 16.

\section{HASIL DAN PEMBAHASAN}

Hasil pengamatan menunjukkan bahwa pada lahan bekas persawahan Desa Tambak Sumur, Kecamatan Waru, Kabupaten Sidoarjo ada 16 spesies capung dan capung-jarum yang termasuk ke dalam 3 famili yaitu Coenagrionidae (Zygoptera), Aeshnidae dan Libellulidae (Anisoptera). Berdasarkan data dari International Union for Conservation Nature (IUCN) dari spesies yang ditemukan satu di antaranya berkategori hampir terancam, near-threatened (NT) yaitu Teinobasis euglena Lieftinck, 1934, satu spesies lainnya kategori kekurangan data, data deficient (DD) yaitu Neurothemis feralis
(Burmeister), dan yang terakhir kategori not evaluated (NE) yaitu Zyхотma obtusum Albarda, 1881 (Dow, 2013, 2019).

T. euglena dengan kategori Nearthreatened (NT) merupakan spesies yang tersebar pada beberapa tempat di Pulau Sumatera dan Jawa (Dow, 2019). Spesies ini biasa ditemukan pada kubangan air dengan tutupan kanopi di tengah kebun atau hutan kering dataran rendah (Setiyono et al., 2017). Spesies ini selalu ditemukan saat siang hari di permukiman yang bersebelahan langsung dengan rawa-rawa. Faktor makanan berupa larva nyamuk sebagai mangsa spesies ini yang banyak terdapat di daerah permukiman diperkirakan menjadi penyebab kehadiran spesies ini.

$N$. feralis dengan kategori (DD) tersebar di Pulau Jawa dan Krakatau dengan individu jantan memiliki sayap gelap meluas dan melengkung ke arah dasar sayap (Dow, 2013; Seehausen, 2017). Pada lokasi penelitian spesies ini sering ditemukan pada tumbuhan Famili Poaceae dengan tinggi antara 30-50 cm yang berdekatan dengan semak-semak. Lokasi tersebut merupakan daerah perairan berupa rawa-rawa dengan tutupan tumbuhan air Ipomoea aquatica (kangkung air) (Convolvulaceae) dan Eichhornia crassipes (eceng gondok) (Pontederiaceae). Selain itu, $N$. feralis biasanya ditemukan di sekitar perairan dengan tutupan tumbuhan Lemnaceae.

Z. obtusum dengan kategori NE dan tidak tercantum dalam IUCN merupakan spesies yang mudah dijumpai saat pagi atau senja dan biasanya terbang rendah di atas air untuk mencari mangsa. Spesies ini beristirahat saat siang hari di tumbuhan bambu pada bagian ujung tajuk. Di lokasi penelitian, spesies ini sangat kompetitif dan saling memperebutkan teritorialnya sehingga satu lokasi hanya terdapat satu individu. Berdasarkan hasil analisis kehadiran (FR), Orthetrum sabina (Drury, 1770) memiliki frekuensi kehadiran tertinggi dengan nilai $60 \%$ yang dapat diartikan sebagai tingginya daya adaptasi 
Muhammad Muhibbuddin Abdillah, Inventarisasi Jenis dan Studi Komposisi Pada Capung (Anisoptera) dan Capung-Jarum (Zygoptera) di Kawasan Kampung Baru, Desa Tambak Sumur, Kecamatan Waru, Kabupaten Sidoarjo, Jawa Timur Jurnal Biolokus: Jurnal Penelitian Pendidikan Biologi Dan Biologi Vol.3 (2)

spesies (Tabel 1). O. sabina merupakan spesies yang tersebar mulai dari ketinggian $0-2300 \mathrm{~m}$ dpl dan biasa ditemukan di sekitar perairan lotik maupun lentik seperti kolam, sawah, irigasi dan semak-semak. O. sangat toleran dengan kadar garam yang tinggi serta kerusakan habitat (Mitra, 2020). Pada lahan bekas persawahan yang telah berubah menjadi permukiman ditemukan juga spesies tersebut. O. sabina sangat toleran dengan polusi organik pada perairan seperti kondisi pada aliran drainase (Nugrahani et al., 2014)

Tabel 1. Persebaran Odonata di Kawasan Kampung Baru, Desa Tambak Sumur, Kecamatan Waru, Kabupaten Sidoarjo, Jawa Timur.

\begin{tabular}{|c|c|c|c|c|c|c|c|c|c|c|}
\hline \multirow{2}{*}{ Subordo } & \multirow{2}{*}{ Famili } & \multirow{2}{*}{ Spesies } & \multicolumn{5}{|c|}{ Persebaran } & \multirow{2}{*}{ FK \% } & \multirow{2}{*}{$\mathbf{K}$} & \multirow{2}{*}{ IUCN } \\
\hline & & & 1 & 2 & 3 & 4 & 5 & & & \\
\hline \multirow{4}{*}{ Zygoptera } & \multirow{4}{*}{ Coenagrionidae } & Agriocnemis femina & & & & $\sqrt{ }$ & & 20 & + & LC \\
\hline & & Ceriagrion praetermissum & & & $\sqrt{ }$ & & & 20 & + & LC \\
\hline & & Ischnura senegalensis & & $\sqrt{ }$ & $\sqrt{ }$ & & & 40 & ++ & LC \\
\hline & & Teinobasis euglena & $\sqrt{ }$ & & & & & 20 & + & NT \\
\hline \multirow{12}{*}{ Anisoptera } & Aeshnidae & Anaciaeschna jaspidea & & & $\sqrt{ }$ & & & 20 & + & LC \\
\hline & \multirow{11}{*}{ Libellulidae } & Acisoma panorpoides & & & & $\sqrt{ }$ & & 20 & + & LC \\
\hline & & Brachythemis contaminata & & & & & $\sqrt{ }$ & 20 & + & LC \\
\hline & & Crocothemis servilia & & & & $\sqrt{ }$ & & 20 & + & LC \\
\hline & & Diplacodes trivialis & $\sqrt{ }$ & & & $\sqrt{ }$ & & 40 & ++ & LC \\
\hline & & Macrodiplax cora & & & $\sqrt{ }$ & & & 20 & + & LC \\
\hline & & Neurothemis feralis & & & & $\sqrt{ }$ & & 20 & + & DD \\
\hline & & Orthetrum sabina & $\sqrt{ }$ & & & $\sqrt{ }$ & $\sqrt{ }$ & 60 & +++ & $\mathrm{LC}$ \\
\hline & & Pantala flavescens & $\sqrt{ }$ & & & $\sqrt{ }$ & & 40 & ++ & $\mathrm{LC}$ \\
\hline & & Rhyothemis phyllis & $\sqrt{ }$ & & & & & 20 & + & $\mathrm{LC}$ \\
\hline & & Tholymis tillarga & & $\sqrt{ }$ & & & $\sqrt{ }$ & 40 & ++ & $\mathrm{LC}$ \\
\hline & & Zyхотma obtusum & & $\sqrt{ }$ & & & & 20 & + & NA \\
\hline
\end{tabular}

Keterangan: (1) Permukiman, (2) Kolam Ikan, (3) Rawa-rawa, (4) Lapangan Rumput dan (5) Aliran Drainase, Frekuensi Kehadiran (FK), Kategori Frekuensi (K), Sangat Jarang (+), Jarang (++), Sedang (+++). Sumber: (Boudot et al., 2016; Clausnitzer, 2016; Clausnitzer et al., 2018; Dow, 2013, 2017a, 2017b, 2019, 2020; Mitra, 2020; Sharma, 2010, 2020; Sharma \& Clausnitzer, 2016; Subramanian, 2020; Subramanian \& Dow, 2010).

Frekuensi Kehadiran spesies adalah suatu kriteria dalam mengukur kehadiran spesies dalam satu ruang lingkup habitat (Krebs, 1989). Sumber daya, makanan, faktor lingkungan abiotik (suhu dan kelembapan) serta daya jelajah spesies merupakan faktor utama yang memengaruhi kehadiran suatu spesies (Abdillah, 2018; Herlambang et al., 2016). Tingginya frekuensi kehadiran $O$. sabina merupakan gambaran bahwa spesies ini memiliki daya adaptasi yang tinggi sehingga ditemukan pada permukiman, lapangan rumput, dan aliran drainase. Barus (2004), menyebutkan bahwa $\mathrm{FK}=0-25 \%$ berarti kehadiran sangat jarang, $\mathrm{FK}=25-50 \%$ kehadiran jarang, $\quad$ FK $=50-75 \%$ berarti kehadiran sedang, dan jika $\mathrm{FK}=75-100 \%$ berarti tingkat kehadiran absolut.

Komposisi famili pada masing-masing lokasi penelitian didominasi oleh Famili Libellulidae. Aliran drainase adalah lokasi yang hanya dihuni oleh capung dari Fami Libellulidae tanpa adanya spesies dari famili lain (Gambar 2). Brachythemis contaminata (Fabricius, 1793) adalah spesies yang mudah dijumpai pada lokasi tersebut, capung ini 
Muhammad Muhibbuddin Abdillah, Inventarisasi Jenis dan Studi Komposisi Pada Capung

(Anisoptera) dan Capung-Jarum (Zygoptera) di Kawasan Kampung Baru, Desa Tambak Sumur, Kecamatan Waru, Kabupaten Sidoarjo, Jawa Timur

Jurnal Biolokus: Jurnal Penelitian Pendidikan Biologi Dan Biologi Vol.3 (2)

secara umum biasa ditemui pada kolam maupun aliran sungai (Abdillah et al., 2019).

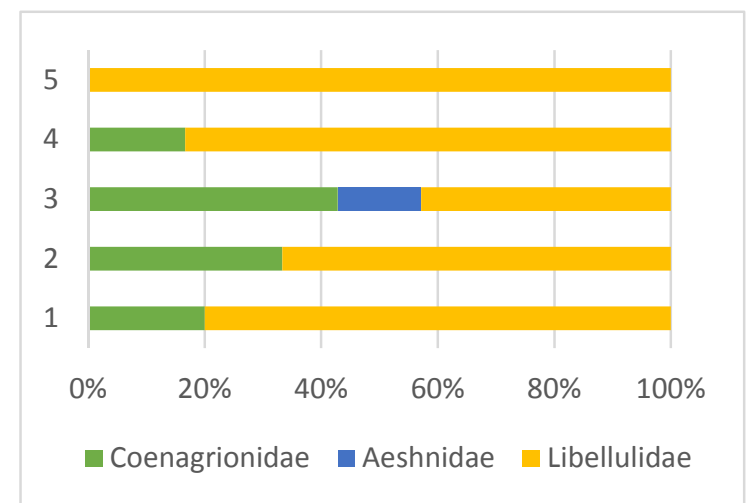

Gambar 2. Grafik Komposisi Famili, (1) Permukiman, (2) Kolam Ikan, (3) Rawa-rawa, (4) Lapangan Rumput dan (5) Aliran Drainase. (Sumber: Dok. Pribadi, 2020)

Rawa-rawa di Kawasan Kampung Baru menjadi lokasi dengan keanekaragaman famili paling lengkap. Pada lokasi lain hanya ditemukan satu hingga dua famili yaitu Coenagrionidae dan Libellulidae, pada lokasi ini terdapat famili lain yaitu Aeshnidae. Famili Aeshnidae yang ditemukan pada lokasi ini adalah Anaciaeschna jaspidea (Burmeister, 1839). Spesies ini pada umumnya ditemukan pada sungai atau sawah (Setiyono et al., 2017). Spesies ini pada lokasi pengamatan ditemukan hinggap di sekitar tumbuhan kangkung air.

Dendogram (Gambar 3) menunjukkan bahwa jika dipotong pada tingkat penyimpangan 10\% maka terdapat tiga kelas. Kelas pertama adalah kolam ikan (2) dan aliran drainase (5) yang berupa ekosistem air tawar buatan manusia. Kelas ke-dua adalah permukiman (1) dan lapangan rumput (4) yaitu ekosistem daratan buatan manusia. Kelas ketiga adalah rawa-rawa (3) dengan ekosistem yang lebih jarang dicampuri manusia. Pemisahan kelas ke-tiga dengan kelas pertama dan ke-dua terjadi pada angka yang lebih tinggi juga menunjukkan bahwa wilayah tersebut awalnya adalah berupa sawah atau rawa-rawa.

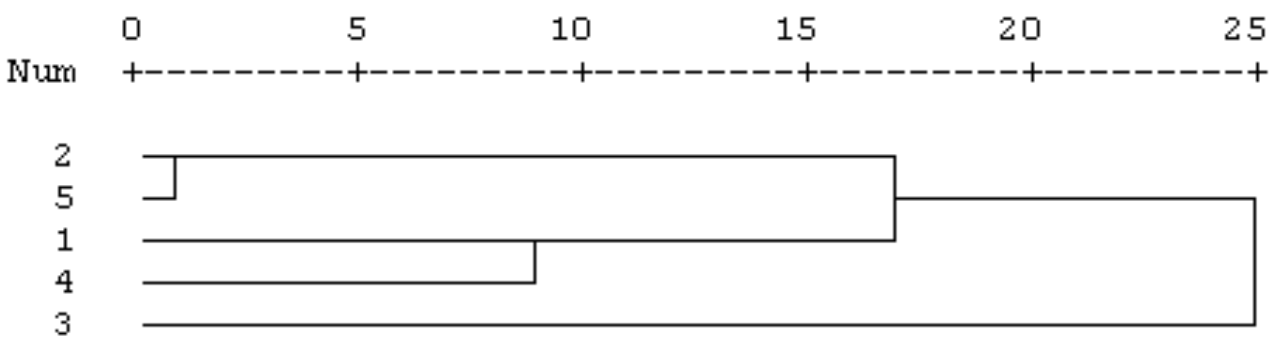

Gambar 3. Dendogram Persamaan Komposisi Spesies,

(1) Permukiman, (2) Kolam Ikan, (3) Rawa-rawa, (4) Lapangan Rumput dan (5) Aliran Drainase.

(Sumber: Dok. Pribadi, 2020)

Kelas pertama, spesies yang ditemukan pada kedua lokasi adalah Tholymis tillarga Fabricius, 1798. Spesies ini memiliki kebiasaan terbang rendah di atas sungai maupun kolam pada pagi hingga sore hari (Abdillah et al., 2019).

Diplacodes trivialis (Rambur, 1842) dan $O$. sabina merupakan spesies yang dapat ditemukan pada kedua lokasi kelas ke-dua. Kedua spesies tersebut adalah spesies yang sangat toleran dengan perubahan lingkungan (Nugrahani et al., 2014). Kedua spesies tersebut memiliki tren populasi yang stabil walaupun perubahan lingkungan dan alih fungsi lahan terus terjadi (Mitra, 2020; Subramanian, 2020).

Pada kelas ketiga, beberapa spesies tidak ditemukan di lokasi lainnya, yaitu Ceriagrion praetermissum (Lieftinck, 1929) A. jaspidea dan Macrodiplax cora (Brauer, 1867). Ketiga spesies tersebut biasa ditemukan pada habitat sawah yang merupakan kondisi wilayah sebelum berubah menjadi permukiman (Setiyono et al., 2017).

Perubahan lahan dari sawah menjadi permukiman dan beberapa fitur pendukung 
Muhammad Muhibbuddin Abdillah, Inventarisasi Jenis dan Studi Komposisi Pada Capung (Anisoptera) dan Capung-Jarum (Zygoptera) di Kawasan Kampung Baru, Desa Tambak Sumur, Kecamatan Waru, Kabupaten Sidoarjo, Jawa Timur Jurnal Biolokus: Jurnal Penelitian Pendidikan Biologi Dan Biologi Vol.3 (2)

kehidupan manusia selalu diikuti dengan perubahan kondisi vegetasi. Keadaan vegetasi baru yang berperan sebagai produsen dalam rantai makanan turut memengaruhi komposisi spesies yang hidup di wilayah tersebut. Sebagai bagian dari rantai makanan, capung juga terpengaruh oleh kondisi vegetasi karena beberapa kebiasaan dan sumber makanan yang erat kaitannya dengan vegetasi tersebut. Sebagai contoh, capung Famili Libellulidae mencari makan, berjemur, dan kawin di sekitar vegetasi semak dan herba. Libellulidae akan hinggap pada pohon ketika malam hari untuk menghindari predator (Abdillah et al., 2018).

\section{PENUTUP}

Hasil inventarisasi capung dan capungjarum di Kawasan Kampung Baru, Desa Tambak Sumur, Kecamatan Waru, Kabupaten Sidoarjo, Jawa Timur menunjukkan ada 16 spesies dari 3 famili. Frekuensi relatif (FR) tertinggi terdapat pada spesies Orthetrum sabina. Berdasarkan hasil dendogram persamaan komposisi spesies antara kelima lokasi penelitian, didapatkan tiga kelas yaitu kelas ekosistem perairan buatan (kolam ikan dan aliran drainase), kelas ekosistem daratan buatan (permukiman dan lapangan rumput) dan kelas rawa-rawa.

\section{REFERENSI}

Abdillah, M. M. (2018). Diversitas Odonata dan Peranannya Sebagai Indikator Kualitas Air di Sumber Clangap dan Sumber Mangli Desa Puncu Kecamatan Puncu Kabupaten Kediri. UIN Sunan Ampel.

Abdillah, M. M., Millah, N., Arroyyan, N., Alifuddin, F., \& Pertiwi, W. (2018). Correlation between Libellulidae diversity and vegetation diversity at Sumber Clangap Village of Puncu, Subdistrict of Puncu, District of Kediri. The Proceeding of the International Symposium on Bioremediation, Biomaterial, Revegation, and Conservation, 27 September, 56-62.
Abdillah, M., Addiniyah, N. R., Millah, N., \& Mubarak, Z. (2019). Serangga uinsa. CV. Rasi Terbit.

Barus, I.T. A. (2004). Pengantar Limnologi Studi Tentang Ekosistem Air Daratan. Medan: USU Press.

Boudot, J. P., Clausnitzer, V., Samraoui, B., Suhling, F., Dijkstra, K. D. B., Schneider, W., \& Paulson, D. R. (2016). Pantala flavescens. The IUCN Red List of Threatened Species 2016. http://dx.doi.org/10.2305/IUCN.UK.20163.RLTS.T59971A65818523.en

Clausnitzer, V. (2016). Tholymis tillarga, Old World Twister. The IUCN red list of threatened 2016. http://dx.doi.org/10.2305/IUCN.UK.20163.RLTS.T60048A83382535.en

Clausnitzer, V., Suhling, F., \& Dow, R. A. (2018). Acisoma panorpoides, Asian Pintail. The IUCN red list of threatened species 2018. http://dx.doi.org/10.2305/IUCN.UK.20181.RLTS.T56259873A56260502.en\%0ACopyr ight:

Dow, R. A. (2013). Neurothemis feralis. The IUCN red list of threatened species 2013. http://dx.doi.org/10.2305/IUCN.UK.20131.RLTS.T169136A1272832.en

Dow, R. A. (2017a). Crocothemis servilia,. The IUCN red list of threatened species. http://dx.doi.org/10.2305/IUCN.UK.20173.RLTS.T163607A80679957.en

Dow, R. A. (2017b). Rhyothemis phyllis,. The IUCN red list of threatened species 2017. http://dx.doi.org/10.2305/IUCN.UK.20171.RLTS.T167448A83383933.en

Dow, R. A. (2019). Teinobasis euglena. The IUCN red list of threatened species 2019. http://dx.doi.org/10.2305/IUCN.UK.20193.RLTS.T135434027A135435336.en

Dow, R. A. (2020). Agriocnemis femina. The IUCN red list of threatened species 2020 . https://dx.doi.org/10.2305/IUCN.UK.20201.RLTS.T167208A83375055.en 
Muhammad Muhibbuddin Abdillah, Inventarisasi Jenis dan Studi Komposisi Pada Capung (Anisoptera) dan Capung-Jarum (Zygoptera) di Kawasan Kampung Baru, Desa Tambak Sumur, Kecamatan Waru, Kabupaten Sidoarjo, Jawa Timur Jurnal Biolokus: Jurnal Penelitian Pendidikan Biologi Dan Biologi Vol.3 (2)

Herlambang, A. E. N., Hadi, M., \& Tarwotjo, U. (2016). Struktur Komunitas capung di kawasan wisata Curug Lawe Benowo Ungaran Barat. Bioma: Berkala Ilmiah Biologi, $\quad$ 18(2), 70. https://doi.org/10.14710/bioma.18.2.70-78

Janra, M. N. (2018). INVENTORY OF DRAGONFLIES AND DAMSELFLIES (ODONATA) IN ANDALAS UNIVERSITY'S LIMAU MANIS CAMPUS COMPLEX, PADANG: USING PHOTOGRAPHICAL APPROACH. Jurnal Natural, 18(2), 85-88. https://doi.org/ 10.24815/jn.v18i2.11133

Kjer, K. M. (2004). Aligned 18s and Insect Philogeny. Syst. Biol. 53(3):506-514, 2004

Krebs, C. J. (1989). Ecological Methodology. Harper \& Row.

Mitra, A. (2020). Orthetrum sabina,. The IUCN red list of threatened species. https://dx.doi.org/10.2305/IUCN.UK.20201.RLTS.T165470A83377025.en

Nugrahani, M. P., Nazar, L., Makitan, T., \& Setiyono, J. (2014). Peluit Tanda Bahaya: Capung Indikator Lingkungan Panduan Penilaian Kualitas Lingkungan Melalui Capung. Indonesian Dragonflies Society.

Rani, F., \& Islami, T. (2014). Kebijakan Pemerintah Indonesia dalam melindungi sumber daya genetik pada pemerintahan Susilo Bambang Yudhoyono Tahun 2013. Transnasional, 6(1), 1247-1255.

Rezzafiqrullah, M., Taradipha, R., Rushayati, S. B., \& Haneda, N. F. (2019). Karakteristik lingkungan terhadap komunitas serangga. Jurnal Pengelolaan Sumberdaya Alam dan Lingkungan (Journal of Natural Resources and Environmental Management), 9(2), 394404.

https://doi.org/https://doi.org/10.29244/jp sl.9.2.394-404

Seehausen, M. (2017). Nomenclature and status of the Neurothemis tullia complex of species (Odonata: Libellulidae). Odonatologica, 46(12), 119-136. https://doi.org/10.5281/zenodo.572361
Setiyono, J., Diniarsih, S., Budi, N. S., \& Oscilata, E. N. R. (2017). Dragonflies of Yogyakarta. Indonesian Dragonflies Society.

Sharma, G. (2010). Brachythemis contaminata. The IUCN red list of threatened species 2010. http://dx.doi.org/10.2305/IUCN.UK.20104.RLTS.T167368A6335347.en

Sharma, G. (2020). Macrodiplax cora,. The IUCN red list of threatened species 2020. https://dx.doi.org/10.2305/IUCN.UK.20201.RLTS.T167478A83378965.en

Sharma, G., \& Clausnitzer, V. (2016). Ischnura senegalensis. The IUCN red list of threatened species.

Subramanian, K. A. (2020). Diplacodes trivialis. The IUCN red list of threatened species 2020. https://dx.doi.org/10.2305/IUCN.UK.20201.RLTS.T167372A83371487.en

Subramanian, K. A., \& Dow, R. A. (2010). Ceriagrion praetermissum. The IUCN red list of threatened species 2010. http://dx.doi.org/10.2305/IUCN.UK.20104.RLTS.T169147A6573101.en\%0ACopyright

Yuliawati, A. K., Pribadi, K. N., \& Hadian, M. S. D. (2016). Geotourism Resources as Part of Sustainable Development in Geopark Indonesia. 15, 962-965. https://doi.org /10.2991/gcbme-16.2016.178 